\title{
Morbidity pattern amongst elderly patients presenting at a primary care clinic in Nigeria
}

\author{
Authors: \\ Lawrence A. Adebusoye ${ }^{1}$ \\ Modupe M. Ladipo ${ }^{1}$ \\ Eme T. Owoaje ${ }^{2}$ \\ Adetola M. Ogunbode ${ }^{1}$ \\ Affiliations: \\ ${ }^{1}$ General Outpatients \\ Department, University \\ College Hospital, Nigeria \\ ${ }^{2}$ Department of \\ Community Medicine, \\ University College Hospital, \\ Nigeria \\ Correspondence to: \\ Lawrence Adebusoye \\ Email: \\ larrymacsoye@yahoo.com \\ Postal address: \\ General Outpatients \\ Department, University \\ College Hospital, PMB \\ 5116, Ibadan, Nigeria \\ Dates: \\ Received: 06 July 2010 \\ Accepted: 14 Oct. 2010 \\ Published: 11 Apr. 2011 \\ How to cite this article: \\ Adebusoye L A, Ladipo M \\ $M$, Owoaje E T, Ogunbode \\ A M. Morbidity pattern \\ amongst elderly patients \\ presenting at a primary \\ care clinic in Nigeria .Afr J \\ Prm Health Care Fam Med. \\ 2011;3(1), Art. \#211, 6 \\ pages. doi:10.4102/phcfm. \\ v3i1.211
}

C) 2011. The Authors. Licensee: OpenJournals Publishing. This work is licensed under the Creative Commons Attribution License.
Background: The elderly comprise the fastest-expanding age group globally, with the greatest increase occurring in developing countries. Disease and deteriorating health are implicitly assumed to be associated with ageing, as chronic medical illnesses mostly present with increasing age.

Objectives: To describe the morbidity pattern of elderly patients presenting at the General Outpatients Clinic of the University College Hospital, Ibadan, Nigeria.

Method: This was a cross-sectional descriptive study of 500 elderly respondents who presented at the clinic between September 2004 and April 2005. They were interviewed according to the format of the electronic, second revision of the International Classification of Primary Care (ICPC-2-E) questionnaire. Main outcome measurements were the prevalence of various morbidities, self-reported health status and socio-demographic characteristics. Body mass index (BMI) was used to assess respondents' nutritional status.

Results: Respondents were found to under-report their actual health problems. The mean \pm s.d of self-reported health problems was $1.7 \pm 0.9$ (range 1-6), while the mean \pm s.d of diagnosed morbidities was $2.7 \pm 1.4$ (range 1-8). The most prevalent morbidities were hypertension $(40.0 \%)$, cataracts $(39.4 \%)$ and osteoarthritis $(26.8 \%)$. The prevalence of anaemia was $8.0 \%$ (females $=11.2 \%$; males $=2.6 \%$ ), and it was significantly associated with gender $(p=0.001)$. Nutritional status indicated a high prevalence of overweight and obesity (51.8\%), which was significantly higher amongst the female respondents than the males $(p=0.001)$.

Conclusion: The prevalence of chronic medical illnesses was high amongst the elderly in this setting. In addition, the elderly under-reported their actual health problems. The high prevalence of overweight and obesity amongst the elderly in this setting calls for public health action that advocates lifestyle changes to manage the health of the elderly.

\section{Introduction}

The elderly comprise the fastest-growing age group globally, with a steep increase seen in developing countries. There is an implicit assumption that disease and deteriorating health are associated with ageing, ${ }^{1}$ although studies on elderly people have debunked this assumption. ${ }^{2}$ Various studies have shown that most elderly people maintain good health until advanced age. Africa has the lowest average life expectancy (51.4 years) ${ }^{3}$ compared to regions like Asia (66.3 years), Latin America (69.2 years), Europe (73.3 years) and North America (76.9 years).$^{4}$ Current estimates indicate that the elderly constitute $6 \%$ of Nigeria's population. ${ }^{5}$

Changing demographic transition stages have affected the population of the elderly worldwide. Developed countries tend to be at the fourth stage of demographic transition, where both the birth rate and the death rate are low and population growth slows or even stops, resulting in a large number of elderly people within a dwindling population. ${ }^{3}$ In contrast, the sub-Saharan region, including Nigeria, is generally still at the second stage of demographic transition, where the death rate begins to drop amidst a birth rate that remains high. This leads to a growing population with a longer life expectancy and thus a larger population of elderly people. This demographic transition occurred over a long period in developed countries, but only a short period of time in sub-Saharan Africa. The increasing elderly population in sub-Saharan Africa has led to an increased demand for health and social services. ${ }^{3}$

The elderly usually suffer from multiple pathologies. Clausen et al. ${ }^{1}$ found an average of 5.2 health problems per elderly person living in the Mmankgodi village, Botswana. Other characteristics of the morbidity pattern amongst the elderly are the presence of co-morbidities, non-specific presentation of diseases, impaired drug metabolism and deranged social factors. ${ }^{1}$ Ogunniyi et al. ${ }^{6}$ found that amongst the Idikan community in Ibadan, $59.4 \%$ of the elderly population studied had poor or reduced health. The main health problems were hypertension $(29.0 \%)$, visual 
impairment $(12.1 \%)$, cataracts $(8.1 \%)$, osteoarthritis $(6.7 \%)$ and neurological problems $(5.2 \%){ }^{6}$

With an increasing elderly population in Nigeria, better documentation of their health profiles is needed to inform policy makers of the health problems which they present with. At present geriatrics has not been fully established as a specialty in Nigeria and there is little information about the morbidity pattern of the elderly to form the basis of any meaningful plan of action to improve the quality of life of this section of the population. Furthermore, most studies regarding the morbidity pattern of the elderly in Nigeria have been community based. ${ }^{6}$ Hospital-based data from primary care settings are required for effective planning of health services for the rapidly growing elderly population.

\section{Ethical consideration}

Approval for the study was obtained from the Head of the General Outpatients Department at UCH and the joint University of Ibadan-UCH Ethical Review Board. Each respondent gave informed consent for participation in the study before examination and administration of the questionnaire.

\section{Methods}

\section{Materials}

The study included 500 male and female patients aged 60 years and older who presented at the General Outpatients Clinic at the Univeristy College Hospital (UCH), Ibadan. The age of the respondents was determined by direct recall, association with historical events, the age at marriage and the age at birth of their first child. The respondents were recruited from September to November 2004 (rainy season), and again from February to April 2005 (Harmattan season). This made the seasonal comparison of some morbidities possible. On average, 892 new adult patients were seen at the clinic per month, of whom elderly patients constituted 112 (12.6\%).

\section{Setting}

This study was conducted at the General Outpatients Clinic of the UCH, Ibadan, the capital city of Oyo state, Nigeria. Founded in 1957, UCH is a tertirary academic institution with 1000 beds. Patients from across Nigeria and the West-African sub-region are referred to UCH. The General Outpatients Clinic serves as a primary care clinic within a tertiary hospital setting, as most patients seen at $\mathrm{UCH}$ are managed at first contact, and very few are subsequently referred to specialty units and paramedical services within $\mathrm{UCH}$. The clinic is run by consultant family physicians and postgraduate resident doctors in Family Medicine.

\section{Design}

This was a cross-sectional descriptive study which assessed the morbidity pattern of elderly people who were recruited using universal sampling. Respondents who met the inclusion criteria were recruited every morning from the triaging (sorting) hall as they presented at the clinic. A technologist from the laboratory department administered the questionnaire to all consenting respondents. A urine and a packed cell volume (PCV) blood sample were collected from each respondent in, respectively, a labelled universal bottle and heparinised capillary tubes immediately afterwards. Before the departure of a respondent, the questionnaire was checked for completeness and the urine and the blood samples were checked for correctness with regard to the respondent's identification number.

\section{Procedure}

The respondents were interviewed using a structured questionnaire based on the electronic, second version of the International Classification of Primary Care (ICPC-2-E) questionnaire as developed by the World Organization of Family Doctors. ${ }^{7}$ The questionnaire has previously been used in an African study. ${ }^{1}$ The ICPC-2-E assesses health problems related to (1) general signs and symptoms, (2) blood, (3) digestive system, (4) eyes, (5) ears, (6) circulatory system, (7) musculoskeletal system, (8) mental illness, (9) neurology, (10) respiratory system, (11) skin, (12) endocrine, metabolic and nutritional functions, (13) urinary system, (14) female genital, and (15) male genital system.

During this study the questionnaire sought information on the respondents' socio-demographic data as well as other information regarding self-reported health problems (presenting complaints) and doctor-evaluated health problems. Laboratory analysis of PCV and urinalysis were performed for every respondent. Urinalysis is the cheapest and most commonly used method to screen for diabetes mellitus at the primary care level in Nigeria, while PCV analysis was used to detect anaemia.

For anthropometric measurements height was measured to the nearest centimetre using a stadiometer (Seca, Hanover, USA). Weight was measured to the first decimal (kg) using a weighing scale [Hana, Shenzhen]. The zero mark was checked after every reading for accuracy. The body mass index (BMI) was calculated as weight/height ${ }^{2}$. BMI values of lower than 18.4 were defined as underweight, 18.5-24.9 as normal, 25.0-29.9 as overweight and higher than 30.0 as obese. $^{8}$

Blood pressure was measured with an Accoson mercury sphygmomanometer (Accoson, Essex), which had been calibrated and validated before use. The patients were seated comfortably with their left arm exposed and supported at the level of the heart and their feet on the floor. Patients were allowed to relax and measurement started after 5 minutes' rest. Appropriate cuff sizes were used for each patient, encircling at least $80 \%$ of the arm. The appearance of the first Korotkoff sound was taken as the systolic blood pressure and the diastolic blood pressure was recorded at the disappearance of the fifth Korotkoff sound. Two readings, separated by $2 \mathrm{~min}$, were averaged for the reported blood pressure measurement. ${ }^{9}$ Stage 1 hypertension was defined as 
systolic blood pressure of 140-159 $\mathrm{mmHg}$ and diastolic blood pressure of $90-99 \mathrm{mmHg}$, while stage 2 was a systolic blood pressure higher than $160 \mathrm{mmHg}$ and diastolic blood pressure higher than $100 \mathrm{mmHg} .{ }^{10} \mathrm{PCV}$ below $30 \%$ was taken as an indication of anaemia. Some of the respondents were referred to other specialist clinics within the facility for definitive diagnoses.

The British Registrar General's classification was used for classification of social class. ${ }^{11}$

\section{Statistical analysis}

The questionnaires were cross-checked after each interview and coded serially. SPSS (version 15) was used for data entry, cleaning and analysis. Descriptive statistics were used to describe socio-demographic characteristics of the respondents. Appropriate charts were used to illustrate categorical variables. Chi-square statistics were used to assess association between categorical variables. Statistical significance was set at $p \leq 0.05$

\section{Results}

The socio-demographic characteristics of the study sample are shown in table1. Of the 500 elderly respondents, 311 $(62.2 \%)$ were female and $189(37.8 \%)$ were male. This gave a female : male ratio of 1.7:1. Their mean age was 67.8 years (s.d $=7.1$ years, range 60-104 years). The modal age group was 60-69 years. The monthly income of the respondents ranged from 2000 naira to 175000 naira (equivalent to $\$ 13.33$ $\$ 1166.67)$, with a median income of 5000 naira, which was much lower than the Nigeria's minimum wage of 11500 naira. The majority of respondents $(n=295,59.0 \%)$ were married, $170(34.0 \%)$ were widowed, $24(4.8 \%)$ were separated from their spouses, $10(2.0 \%)$ were divorced and one respondent

TABLE 1: Socio-demographic characteristics of respondents by gender distribution.

\begin{tabular}{|c|c|c|c|c|c|c|}
\hline \multirow[t]{2}{*}{ Characteristic } & \multicolumn{2}{|c|}{ Male } & \multicolumn{2}{|c|}{ Female } & \multicolumn{2}{|c|}{ Total } \\
\hline & $n$ & $\%$ & $n$ & $\%$ & $N$ & $\%$ \\
\hline \multicolumn{7}{|l|}{ Age (years) } \\
\hline $60-64$ & 57 & 30.2 & 119 & 38.3 & 176 & 35.2 \\
\hline $65-69$ & 44 & 23.3 & 82 & 26.3 & 126 & 25.2 \\
\hline $70-74$ & 51 & 27.0 & 62 & 20.0 & 113 & 22.6 \\
\hline $75-79$ & 20 & 10.6 & 20 & 6.4 & 40 & 8.0 \\
\hline $80-84$ & 15 & 7.9 & 14 & 4.5 & 29 & 5.8 \\
\hline$\geq 85$ & 2 & 1.0 & 14 & 4.5 & 16 & 3.2 \\
\hline \multicolumn{7}{|l|}{ Marital status } \\
\hline Married & 153 & 81.0 & 142 & 45.7 & 295 & 59.0 \\
\hline Single & 1 & 0.5 & 0 & 0.0 & 1 & 0.2 \\
\hline Divorced & 4 & 2.1 & 6 & 1.9 & 10 & 2.0 \\
\hline Widowed & 20 & 10.6 & 150 & 48.2 & 170 & 34.0 \\
\hline Separated & 11 & 5.8 & 13 & 4.2 & 24 & 4.8 \\
\hline \multicolumn{7}{|l|}{ Social class } \\
\hline 1 & 5 & 2.7 & 0 & 0.0 & 5 & 1.0 \\
\hline II & 31 & 16.4 & 21 & -6.8 & 52 & 10.4 \\
\hline III & 32 & 16.9 & 2 & 0.6 & 34 & 6.8 \\
\hline IV & 49 & 25.9 & 31 & 10.0 & 80 & 16.0 \\
\hline v & 72 & 38.1 & 259 & 82.6 & 329 & 65.8 \\
\hline \multicolumn{7}{|l|}{ Income } \\
\hline Below poverty line $(<\$ 1 /$ day $)$ & 78 & 41.3 & 184 & 59.2 & 262 & 52.4 \\
\hline Above poverty line (> $\$ 1 /$ day) & 111 & 58.7 & 127 & 40.8 & 238 & 47.6 \\
\hline \multicolumn{7}{|l|}{ Number of children alive } \\
\hline $1-2$ & 9 & 4.8 & 33 & 10.6 & 42 & 8.4 \\
\hline $3-4$ & 30 & 15.9 & 110 & 35.4 & 140 & 28.0 \\
\hline$\geq 5$ & 150 & 79.3 & 168 & 54.0 & 318 & 63.6 \\
\hline \multicolumn{7}{|l|}{ Living arrangement } \\
\hline Alone & 10 & 5.3 & 44 & 14.1 & 54 & 10.8 \\
\hline With spouse in own home & 24 & 12.7 & 45 & 14.5 & 69 & 13.8 \\
\hline With children or grandchildren in own home & 140 & 74.1 & 86 & 27.7 & 226 & 45.2 \\
\hline With children or grandchildren in their home & 8 & 4.2 & 110 & 35.4 & 118 & 23.6 \\
\hline With other relatives & 7 & 3.7 & 26 & 8.3 & 33 & 6.6 \\
\hline \multicolumn{7}{|l|}{ Family support } \\
\hline Self & 80 & 42.3 & 45 & 14.5 & 125 & 25.0 \\
\hline Spouse & 2 & 1.1 & 9 & 2.9 & 11 & 2.2 \\
\hline Children or grandchildren & 100 & 52.9 & 248 & 79.7 & 348 & 69.6 \\
\hline Other relatives & 4 & 2.1 & 8 & 2.6 & 12 & 2.4 \\
\hline Friends & 3 & 1.6 & 1 & 0.3 & 4 & 0.8 \\
\hline
\end{tabular}

Source: World Bank 2004.12

$n$, number. 
TABLE 2: Self-reported health problems of respondents using ICPC classification.

\begin{tabular}{lcc}
\hline ICPC classification & Number of presenting complaints \\
\cline { 2 - 3 } & $\boldsymbol{n}$ & $\%$ \\
\hline General body symptoms & 206 & 41.2 \\
Blood & 3 & 0.6 \\
Digestive & 78 & 15.6 \\
Eye & 99 & 19.8 \\
Ear & 7 & 1.4 \\
Cardiovascular & 30 & 6.0 \\
Musculoskeletal & 130 & 26.0 \\
Neurology & 132 & 26.4 \\
Mental illness & 53 & 10.6 \\
Respiratory & 51 & 10.2 \\
Skin & 24 & 4.8 \\
Endocrine, metabolic, nutrition & 26 & 5.2 \\
Urinary & 30 & 6.0 \\
Genital & 2 & 0.4 \\
\hline
\end{tabular}

$n$, number.

TABLE 3: Morbidity pattern among respondents.

\begin{tabular}{|c|c|c|}
\hline \multirow[t]{2}{*}{ Morbidity } & \multicolumn{2}{|c|}{$N=500$} \\
\hline & $n$ & $\%$ \\
\hline Hypertension & 200 & 40.0 \\
\hline Cataracts & 197 & 39.4 \\
\hline Osteoarthritis & 134 & 26.8 \\
\hline Skin ulcers (wounds) & 75 & 15.0 \\
\hline Diabetes & 66 & 13.2 \\
\hline Psychosomatic disorders & 65 & 13.0 \\
\hline Depression & 51 & 10.2 \\
\hline Malaria & 41 & 8.2 \\
\hline Anaemia & 40 & 8.0 \\
\hline Heart failure & 37 & 7.4 \\
\hline Vertigo & 33 & 6.6 \\
\hline Pterygium & 28 & 5.6 \\
\hline Upper respiratory tract Infection & 26 & 5.2 \\
\hline Hearing impairment & 25 & 5.0 \\
\hline Goitre & 23 & 4.6 \\
\hline Seizure disorders & 19 & 3.8 \\
\hline $\mathrm{BPH}$ & 16 & 3.2 \\
\hline Glaucoma & 15 & 3.0 \\
\hline Peptic ulcer disease & 15 & 3.0 \\
\hline Lipoma & 13 & 2.6 \\
\hline Malignancies & 11 & 2.2 \\
\hline Eczema & 11 & 2.2 \\
\hline Cerebrovascular disease & 11 & 2.2 \\
\hline Corneal opacity & 11 & 2.2 \\
\hline Tuberculosis & 9 & 1.8 \\
\hline Chronic obstructive pulmonary disease & 9 & 1.8 \\
\hline Chronic renal insufficiency & 8 & 1.6 \\
\hline Chronic liver disease & 8 & 1.6 \\
\hline Psychosis & 7 & 1.4 \\
\hline Gastroenteritis & 6 & 1.2 \\
\hline Urinary tract infection & 6 & 1.2 \\
\hline Asthma & 5 & 1.0 \\
\hline Allergic conjunctivitis & 5 & 1.0 \\
\hline Viral conjunctivitis & 4 & 0.8 \\
\hline Fissure in ano & 3 & 0.6 \\
\hline Haemorrhoids & 3 & 0.6 \\
\hline Cellulitis & 3 & 0.6 \\
\hline Hernia & 3 & 0.6 \\
\hline Head injury & 3 & 0.6 \\
\hline Hepatitis & 2 & 0.4 \\
\hline Bell's palsy & 2 & 0.4 \\
\hline HIV/AIDS & 2 & 0.4 \\
\hline Erectile dysfunction $^{+}$ & 93 & 49.2 \\
\hline Others & 5 & 1.0 \\
\hline
\end{tabular}

Some respondents presented with multiple morbidities.

$n$, number; BPH, Benign prostatic hyperplasia.

${ }^{+}$, Erectile dysfunction only occurs in men. was single. More than half the respondents $(n=274,54.8 \%)$ were still employed. Almost half of the respondents $(n=226$, $45.2 \%$ ) had their children and/or grandchildren living with them, while $13.8 \%$ were currently living with their spouses in their own home. The majority of the respondents (52.4\%) lived below the World Bank's poverty line of $\$ 1$ a day. ${ }^{12}$

Based on the ICPC 871 health problems were self-reported, with an average of 1.7 health problems per respondent (range $1-6)$. The majority of problems $(n=206,41.2 \%)$ related to general body symptoms like fever, body pains and malaise. Almost an equal number of neurological and musculoskeletal problems were reported $(n=132,26.4 \%$ and $n=130,26.0 \%$ respectively). In addition, 99 respondents(19.8\%) reported eye problems such as pain, redness and poor vision (Table 2).

A total of 1349 morbidities were diagnosed amongst the group, with an average of 2.7 per respondent (range 1-8). Figure 1 illustrates the morbidities according to the ICPC, organised according to gender. The most prevalent morbidities were found in the eyes (males $=50.8 \%$; females $=52.7 \%$ ), and cardiovascular (males $=49.2 \%$; females $=$ $46.3 \%$ ) and musculoskeletal systems (males $=24.9 \%$; females $=28.6 \%$ ). Erectile dysfunction was the only cause of genital morbidity in the male respondents. Distribution across specific morbidities is shown in Table 3. Hypertension (40.0\%) was the most commonly observed morbidity, followed by cataracts (39.4\%) and osteoarthritis (26.8\%).

Anthropometric measurement of the respondents showed their mean height $\pm \mathrm{s} . \mathrm{d}$ to be $1.6 \pm 0.1 \mathrm{~m}($ range $=1.2-1.8 \mathrm{~m})$ and mean weight \pm s.d to be $63.5 \pm 13.5 \mathrm{~kg}$ (range $=30.0$ $109.0 \mathrm{~kg}$ ). At a mean height of $1.62 \pm 0.07 \mathrm{~m}$ the men were significantly taller than the women, whose mean height was $1.53 \pm 0.06 \mathrm{~m}(p=0.001 ; t=15.543)$. However, mean weight of men and women $(63.47 \pm 12.12 \mathrm{~kg}$ vs $63.47 \pm 14.32 \mathrm{~kg})$ was not significantly different ( $p=0.998 ; t=-0.002)$. The mean BMI of the respondents was $25.9 \pm 5.5$ (range $=13.3-47.2$ ), which was significantly higher amongst women (27.1 \pm 5.7$)$ than men $(24.1 \pm 4.6)(p=0.001 ; t=5.876)$. According to BMI cut-off values, the majority $(n=205,41.0 \%)$ were described to have a normal BMI, 160 (32.0\%) were overweight, 106 (21.2\%) were obese and $29(5.8 \%)$ were underweight. More men than women were underweight $(63.3 \%$ vs $36.7 \%)$. Conversely, more women than men were obese $(82.7 \%$ vs $17.3 \%)$. There was a significant association between BMI and gender $\left(\chi^{2}=31.003, p=0.001\right)$.

Laboratory investigation showed the overall prevalence of anaemia to be $8.0 \%$, which was significantly higher among women $(11.2 \%)$ than men $(2.6 \%)\left(\chi^{2}=13.011, p=0.001\right)$. The mean PCV was $35.6 \pm 4.6 \%$ (range $=10.0-50.0 \%$ ); 37.8 $\pm 4.3 \%$ amongst men and $34.2 \pm 4.3 \%$ amongst women. The urinalysis showed that $8.8 \%$ of respondents had glycosuria and $17.8 \%$ had proteinuria.

\section{Discussion Outline of results}

This study highlighted the morbidity pattern of the elderly patients presenting at a general outpatient clinic in Nigeria. 
There was a predominance of female respondents who outnumbered their male counterparts by 1.7 to 1 . This may be attributed to life expectancy, which is higher for women than men. At the time of the study, the life expectancy of Nigerian women was 47 years compared to 46 years for men. ${ }^{13}$ Also, women visit clinics for more frequently than men.

The average number of self-reported health problems (presenting complaints) was less than the average number of morbidities (diagnoses) found amongst the respondents. This shows that the elderly often under-report their health problems and may attribute certain health problems to ageing, thus finding it unnecessary to complain about them to a physician. Finding multiple morbidities per respondent was similar to findings of earlier studies, although fewer were found than for studies in Botswana and India.,14 The average number of morbidities (diagnoses) found amongst the respondents ( 2.7 morbidities) was less than those reported for Botswana (5.2 morbidities) and India (6.0 morbidities). ${ }^{1,14}$ These disparities could be related to cultural perception of illnesses and global differences in the prevalence of diseases. ${ }^{1,6}$ Thus, the importance of a detailed history, comprehensive examination and necessary investigations cannot be emphasised enough in the management of elderly patients.

Eye problems were the most commonly diagnosed morbidity amongst the respondents; cataracts accounted for more than three-quarters of the diagnoses. The high prevalence of cataracts (39.4\%) amongst the respondents may be attributed to cultural fear of surgery, the cost of surgery and the belief that the diminution of vision is the consequence of ageing. In addition, elderly people seldom complain of health problems that do not inflict pain ${ }^{6}$ and they may not readily agree to have eye surgery.

Hypertension was registered in two-fifths of the respondents. Globally, studies have shown that the prevalence of hypertension is increasing and may become a major primary health care problem with an increasing elderly population because blood pressure rises with age in nearly all populations. ${ }^{1,6,10,15,16}$

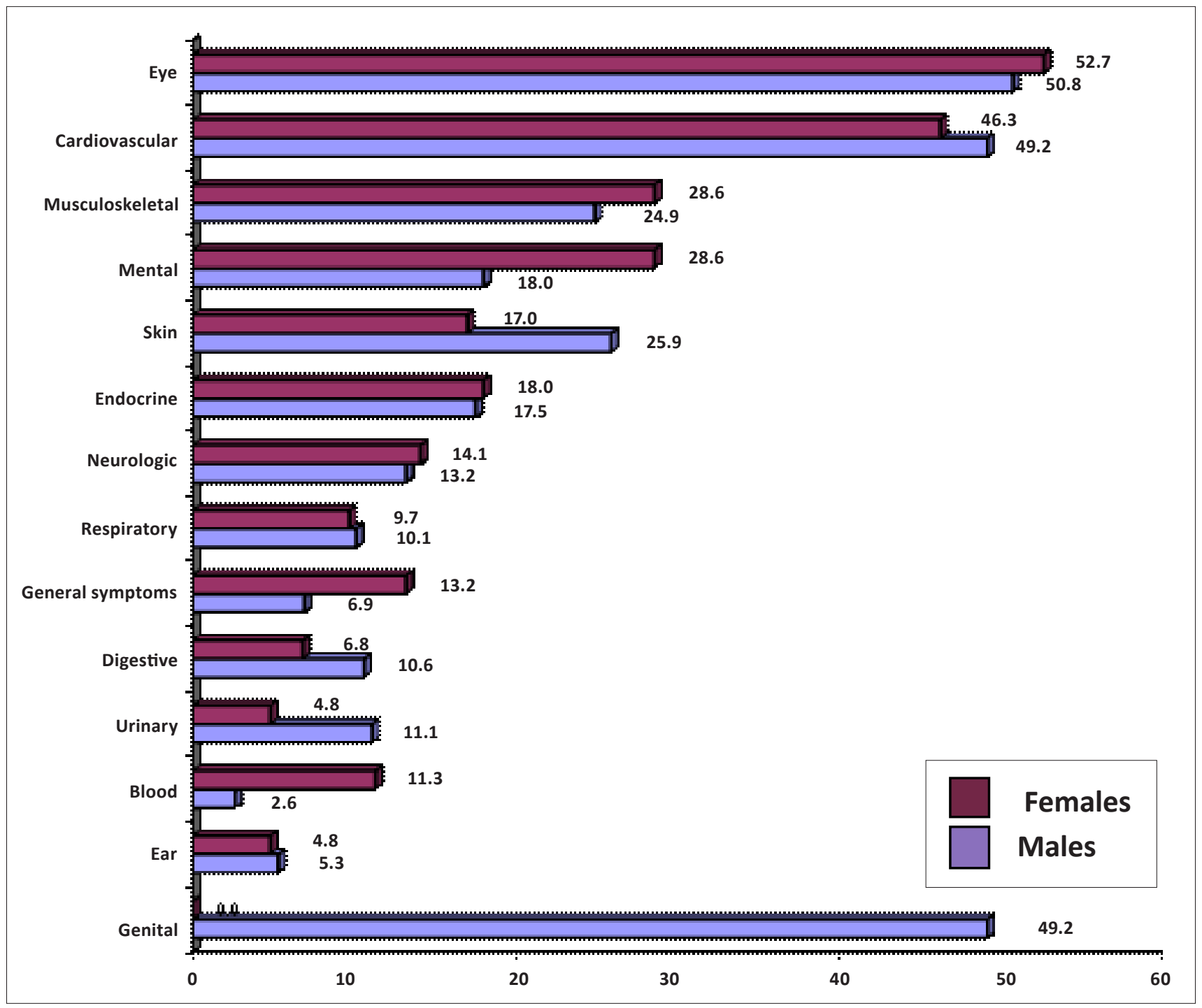

FIGURE 1: Morbidities by gender distribution using ICPC diagnostic classification. 
Musculoskeletal problems were the third most common morbidities found amongst the respondents, with osteoarthritis found amongst $26.8 \%$ of the respondents. In previous studies amongst elderly African communities, osteoarthritis was one of the commonly observed problems. ${ }^{1,6,17}$ Osteoarthritis compromises mobility and consequently tends to impair social and occupational functioning. ${ }^{6}$ It leads to dependency on others, especially family members.

Problems related to mental health were observed more often amongst the female respondents (28.6\%) than the males (18.0\%). The mental problems diagnosed included psychosomatic disorders, depression and psychosis. Uwakwe ${ }^{18}$ reported mental illness to occur at a prevalence of $23.1 \%$ among elderly Nigerians.

At $13.2 \%$ diabetes mellitus was the most common endocrine problem found in this study. This prevalence was higher than what has been reported for the general population in a previous study, ${ }^{19}$ probably because the present study was hospital based and also owing to a higher prevalence of diabetes with advancing age. Thus, the higher prevalence of diabetes in this study might not be surprising.

Overweight and obesity were found in more than half of the respondents. Obesity was significantly more prevalent amongst women than men $(p=0.001)$. Bakare ${ }^{5}$ reported similar findings amongst elderly people in south-western Nigeria. The dietary habits of elderly Nigerians tend towards consumption of high-energy foods like carbohydrates and animal fats. This nutritional habit and minimal physical activity have been implicated as the main reasons for the development of obesity, a situation that is contrary to the recipe for a healthy weight and healthy life. ${ }^{5}$ Anaemia was found in $8.0 \%$ of the respondents and was significantly more prevalent among women than men $(p=0.001)$. Nutritional anaemia is common amongst the elderly due to intrinsic physiological decrease in food intake, taste, smell and gastric emptying, and dysregulation of satiation called 'physiological anorexia of ageing' ${ }^{20}$ Another common cause of anaemia in the elderly is malignancy, which becomes more prevalent with advancing age. ${ }^{20}$

\section{Practical implication}

The physician's goals in the management of the elderly should include health promotion, early disease detection and prevention of frailty when possible. The traditional screening tests used during evaluation of younger patients should not be withheld from the elderly. The elderly should have routine urinalysis and BMI, PCV and blood pressure measurement.

\section{Limitation}

This was a hospital-based study of which the results may not be applicable to the general population.

\section{Recommendation}

The elderly should be encouraged to undergo periodic medical checks at a clinic for routine appraisal of their health status, so as to allow early detection and treatment of their morbidities. More studies on the morbidities of elderly patients presenting at hospitals in developing countries are needed to formulate a longitudinal frontline health care plan for the elderly.

\section{Conclusion}

This study has demonstrated that the elderly present with multiple morbidities and under-report their health problems, which they often attribute to ageing. The most prevalent health problems of the elderly were chronic medical illnesses like hypertension, cataracts, osteoarthritis and psychosomatic disorders - all conditions that are treatable. The high prevalence of overweight and obesity (found in more than half of the respondents) is worrisome when its public health impact is considered. Thus, physicians should include advice on lifestyle modification in their management of elderly patients.

\section{References}

1. Clausen F, Sandberg E, Ingstaad B, Hjortdan P. Morbidity and healthcare utilization among the elderly people in Mmankgodi village. J Epidemiol Community Health. 2000; 54:58-63.

2. Prakash IJ. Health and morbidity in later years. In: Psycho-social Gerontology: Training material for mental health professionals. 1999:6-8.

3. Population Division, United Nations. World Population Prospects: The 2000 Revision [document on the Internet]. United Nations; 2001 [cited 2010 Dec 08]. Available from: http://www.un.org/spanish/esa/population/wpp2000h.pdf

4. Economics and Statistics Administration, Department of Commerce. World population at a glance: 1998 and beyond IB/98-4 [document on the Internet]. Department of Commerce; 1999 [cited 2010 Nov 24]. Available from: http://www. Department of Commerce; 1999
census.gov/ipc/www/wp98.html

5. Bakare OE, Ojofeitimi EO, Akinyemi A. Nutritional assessment and health status of the elderly in southwestern Nigeria. Paper presented at: African Conference on Ageing; 2004 Aug 18-20; Johannesburg, South Africa.

6. Ogunniyi A, Baiyewu $O$, Gureje $O$, et al. Morbidity pattern in a sample of elderly Nigerians resident in Idikan community, Ibadan. West Afr J Med. 2001;20(4):227-231. PMid:11885877

7. Graeme M, Helena B. ICPC-2-E: The Electronic Version ICPC-2. Fam Pract. 2000;17(5):448. doi:10.1093/fampra/17.5.448, PMid:11021908

8. World Health Organization. Physical status: the use and interpretation of anthropometry. Technical report series no. 854. Geneva: World Health Organization; 1995.

9. World Health Organization-International Society of Hypertension. WHO-ISH guidelines for the management of hypertension. J Hypertens. 1999;17:151-183.

10. Joint National Committee on Prevention, Detection, Evaluation, and Treatment of High Blood Pressure. The Seventh Report of the Joint National Committee on Prevention, Detection, Evaluation, and Treatment of High Blood Pressure. The JNC7 Report [document on the Internet]. Department of Health and Human Services; 2003 [cited 2010 Dec 08]. Available from: http://www.nhlbi.nih.gov/guidelines/ hypertension/jnc7full.pdf

11. Rose D. Official social classifications in the UK. Social Research Update. [serial on the Internet]. 1995 [cited 2005 Apr 23]; 9. Available from: http://sru.soc.surrey.ac.uk/ SRU9.html

12. World Bank. Global poverty down by half since 1981 but progress uneven as economic growth eludes many countries. Press release 2004; Available from: http://web.worldbank.org/WBSITE/EXTERNAL/NEWS/0,,contentMDK:20194973 menuPK:34464 pagePK:34370 piPK:34424 theSitePK:4607,00.html

13. Population Reference Bureau. 2008 world population data sheet [document on the Internet]. Population Reference Bureau; 2008 [cited 2010 Feb 20]. Available from http://www.prb.org/pdf08/08wpds_eng.pdf

14. Kamlesh J, Rajesh K, Ajit A. Morbidity profile and its relationship with disability and psychological distress among elderly people in Northern India. Int J Epidemiol. 2004;10:978-987.

15. Joint National Committee on Prevention, Detection, Evaluation, and Treatment of High Blood Pressure. The sixth report of the Joint National Committee on Prevention, Detection, Evaluation, and Treatment of High Blood Pressure. Arch Intern Med. 1997; 57:2413-2446. doi:10.1001/archinte.157.21.2413, PMid:9385294

16. Akinkugbe OO, Ikeme AC, Johnson TO, Akinyanju OO, Mabadeje AF, Oli JM. Noncommunicable diseases in Nigeria. Ibadan: Spectrum Books; 1992.

17. Bella AF, Baiyewu O, Bamigboye A, Adeyemi JD, Ikuesan BA, Jegede RO. The pattern of medical illiness in a community of elderly Nigerians. Cent Afr J Med. 1993;39(6):112-116. PMid:8131198

18. Uwakwe R. The pattern of psychiatric disorders among the aged in a selected community in Nigeria. Int J Geriatr Psychiatry. 2000;15(4):355-362. doi:10.1002/(SICl)1099-1166(200004)15:4<355::AID-GPS126>3.0.CO;2-8

19. World Health Organization. Measurement of glucose in urine. Part 1: Diagnosis and classification of diabetes mellitus and its complications. Geneva: World Health Organization; 2004

20. Hajjar RR, Karmel HK, Denson K. Malnutrition in Aging. The Internet Journal of Geriatrics and Gerontology [serial on the Internet]. 2004 [cited 2010 Dec 08]. 1(1). Available from: http://www.ispub.com/journal/the internet journal of geriatrics and gerontology/volume_1_number_1_24/article/malnutrition_in_äging.html 